\title{
X-Linked Inhibitor of Apoptosis Protein Expression After Ischemic Injury in the Human and Rat Developing Brain
}

\author{
RAND ASKALAN, RYAN SALWESKI, URSULA I. TUOR, JAMIE HUTCHISON, AND CYNTHIA HAWKINS \\ Departments of Pediatrics [R.A.], Critical Care Medicine [R.S., J.H.], and Pediatric Laboratory Medicine [C.H.], Hospital for Sick \\ Children, Toronto, Ontario, Canada M5G 1X8; Institute for Biodiagnostics [U.I.T.], National Research Council, \\ Calgary, Alberta, Canada T2N $4 \mathrm{N1}$
}

\begin{abstract}
X-linked inhibitor of apoptosis protein (XIAP) is a potent suppressor of neuronal death. The aim of this study was to investigate the expression of XIAP after ischemia in the human and rat developing brain. Autopsy specimens from 19 children with neuropathologic diagnosis of focal cerebral ischemic infarct were processed immunohistochemically for XIAP expression. XIAP positive cells were compared in pathologically classified acute (1-4 d), subacute (5-30 d), and chronic (months) strokes vs. age-matched controls with normal brain histology. For the animal studies, ischemia was induced in 1-wk-old rats by unilateral carotid artery occlusion and transient hypoxia. XIAP expression was quantified at four time points after ischemia in the infarct core and peri-infarct area. Neuronal XIAP expression was higher in the penumbra of subacute human infarcts compared with controls $(p<0.05)$. XIAP expression in the peri-infarct of rat pup was highest at $7 \mathrm{~d}$ postischemic injury $(p<0.05)$. The increase in XIAP expression was associated with a reduction in activated caspase- 3 in ischemic neonatal rat brain. Our results demonstrate that XIAP expression postischemic injury is delayed in both species and may continue for several days. Therefore, potentiation of XIAP expression may be neuroprotective in the developing brain. (Pediatr Res 65: 21-26, 2009)
\end{abstract}

$I^{n}$ nhibitors of apoptosis proteins (IAPs) are a physiologically widely expressed gene family of apoptotic suppressors initially identified in the baculoviruses $(1,2)$. Subsequently, six human IAPs have been identified including an X-linked inhibitor of apoptosis protein (XIAP). XIAP is the most potent natural inhibitor of apoptosis, blocking the initiator (caspase-9) and effector (caspase-3 and -7) caspases $(3,4)$ and inhibiting caspase-independent cell death $(5,6)$.

Several studies have shown that apoptosis is a delayed process of neuronal cell death in neonatal animal models of cerebral hypoxic-ischemic injury (7-9). More recently, we have shown delayed apoptosis occurring for several days after stroke in the human developing brain (10). We also showed

Received May 13, 2008; accepted July 30, 2008.

Correspondence: Rand Askalan, M.D., Ph.D., Division of Neurology, Hospital for Sick Children, 555 University Avenue, Toronto, Ontario, Canada M5G 1X8; e-mail: r.askalan@utoronto.ca

This work was funded by the Physicians' Services Incorporated Foundation [R.A.] (R04-45), the Heart and Stroke Foundation of Ontario [R.A.] and Alberta [U.I.T.], the Hospital for Sick Children Research Institute [R.A.], and the Robertson Fund for Cerebral Palsy [U.I.T.]. that activated caspase- 3 continued to be detected for more than $72 \mathrm{~h}$ after stroke, suggesting that antiapoptotic agents are a plausible intervention with a prolonged therapeutic window (10).

Over-expression of XIAP markedly inhibits ischemic damage in the hippocampus and restores neurologic function after global ischemia in the adult rat (11). Wang et al. (12) recently showed that caspase- 3 and -9 activities were virtually abolished, and tissue loss was reduced in XIAP neonatal transgenic mice compared with wild-type mice after hypoxicischemic injury. They also reported an increase in endogenous XIAP in ischemic brain of neonatal wild-type mice. This is in contrast to Russel et al. (13) who reported a reduction in XIAP expression after hypoxic-ischemic injury in the neonatal rat brain. Determining whether there are similar changes in XIAP expression in human brain after stroke is important considering the potential role for XIAP in influencing ischemic cell death. In this study, we are the first to report on the expression of XIAP in the human developing brain after stroke. In addition, we have characterized the temporal and spatial expression of endogenous XIAP in the ischemic neonatal rat brain for comparison with our studies in human specimens.

\section{METHODS}

Human studies. Autopsy specimens registered in the database of the Department of Pathology at the Hospital for Sick Children from January 1990-December 2006 with a pathologic diagnosis of focal cerebral infarct were included in the study. Inclusion criteria were 1) patient was born at term, 2) patient age $<18 \mathrm{y}$, and 3) cerebral infarct had well-defined borders. Patients with global ischemia were excluded. Age-matched brain tissue sections with normal histology were used as controls. This study was approved by the Research Ethics Board at the Hospital for Sick Children.

Tissue preparation and neuropathologic examination of postmortem pediatric human brain specimens were described previously (10). Paraffinembedded $5 \mu \mathrm{m}$ sections stained with hematoxylin and eosin $(\mathrm{H}$ and $\mathrm{E})$ were reviewed by the neuropathologist (C.H.) to confirm the diagnosis of focal ischemic infarct. Age of the infarct was determined based on its pathologic appearance (14). Core of acute infarcts ( $1-4 \mathrm{~d})$ were characterized by eosinophilic neurons with nuclear pyknosis and vacuolation of surrounding parenchyma. Core of subacute infarcts $(5-30 \mathrm{~d})$ were characterized by infiltration by foamy histiocytes, early cavitation, and surrounding astrogliosis and in some cases, vascular proliferation. Core of chronic infarcts (wks-mo/y)

Abbreviations: HRP, horseradish peroxidase; XIAP, X-linked inhibitor of apoptosis protein 
were basically cavities with surrounding astrogliosis and in some cases persistent histiocytes. Normal brain parenchyma directly adjacent to the ischemic "core" is the "penumbra" as defined previously (10). None of the age-matched control brain sections showed any pathologic changes.

Animal studies. The Rice-Vannucci model of unilateral carotid artery occlusion with $8 \%$ hypoxia was used as described previously $(15,16)$. In brief, 1-wk-old Wistar pups of either sex were randomly assigned to control group or transient cerebral hypoxia-ischemia group. The right internal carotid artery was ligated and cut while the animals were under isoflurane-induced anesthesia. In control animals, the carotid artery was isolated but not ligated. All pups after surgery were allowed to recover for $1-2 \mathrm{~h}$ with their dams. Transient ischemia was produced in the hemisphere ipsilateral to the occlusion by subjecting the animals to a hypoxic episode consisting of humidified $8 \%$ oxygen for $1.5 \mathrm{~h}$. Body temperature was maintained at $37.0-37.5^{\circ} \mathrm{C}$ during hypoxia using an incubator. The animals were killed using pentobarbital $(120 \mathrm{mg} / \mathrm{kg})$ at $24 \mathrm{~h}, 48 \mathrm{~h}, 72 \mathrm{~h}$, and $1 \mathrm{wk}(n=4$ per time point) after the hypoxic-ischemic insult. Brains were removed and immediately fixed in $10 \%$ formalin. Animal protocols were approved by the local animal care committees and followed guidelines of the Canadian Council on Animal Care.

Paraffin-embedded coronal sections $(8 \mu \mathrm{m})$ were cut at the level of the hippocampus. One section from each brain was stained with crystal violet using standard techniques for paraffin sections to confirm the presence or absence of an ischemic injury in the hypoxic-ischemic group and the control group, respectively. Core of infarction was defined by loss of normal staining pattern of brain parenchyma. Signs of ischemic injury, in the distribution of the right middle cerebral artery territory, were consistently seen in sections from 16 hypoxic-ischemic rat pups stained with cresyl violet. Pyknotic nuclei were seen in cortex and hippocampus of these animals ipsilateral to the ligated internal carotid artery. The hippocampus was chosen as a readily identifiable representative of this region. Ischemic changes were not seen in the contralateral hemisphere or in the control animals $(n=4)$. Peri-infarct area was defined as the normal brain parenchyma directly adjacent to the infarcted tissue.
Immunohistochemistry. Human and rat pup brain sections were de-waxed in xylene, and hydrated to distilled water through decreasing concentrations of alcohol. Sections were pretreated for heat-induced antigen retrieval technique using EDTA buffer at pH 6.0. Endogenous peroxidase activity was blocked using $\mathrm{H}_{2} \mathrm{O}_{2}$ /methanol and then sections were washed with $0.1 \%$ Triton $100 \mathrm{X}$ for $15 \mathrm{~min}$ and blocked with $1 \%$ BSA/PBS.

Human brain sections were incubated with rabbit anti-XIAP (1:500 from ProSci Inc, Burlington, ON, Canada) overnight at $4^{\circ} \mathrm{C}$, washed, and then incubated with goat anti-rabbit horseradish peroxidase (HRP) (1:100 from BioRad, Mississauga, ON, Canada) at room temperature for $1 \mathrm{~h}$. Rat pup brain sections were incubated with mouse monoclonal anti-XIAP $(1: 100$ from BD Biosciences, Mississauga, ON, Canada), washed and then incubated with goat anti-mouse HRP (1:100 from BioRad). Immunoreactivity in both species was detected by 3,3-diaminobenzidine (DAB) substrate kit for peroxidase (Vector Laboratories, Burlington, ON, Canada). The number of XIAP positive cells were counted in $4-5$ high power fields $(40 \times)$ for each of the core and penumbra of rat and human infarcts using Image $\mathbf{J}$ computer software (National Institutes of Health, Bethesda, MD). The person counting the cells was blinded to the age of the infarct or the time point at which the rat pup was killed postischemic injury.

For activated caspase-3 staining, brain section from rat pups were incubated with rabbit polyclonal anticleaved caspase-3 (Asp-175) antibody (1:400; from Cell Signaling, Pickering, ON, Canada) at $4^{\circ} \mathrm{C}$ for overnight after treating the sections with the same antigen retrieval method described above. Slides were washed and then incubated with Alexa Fluro 488 goat anti-rabbit, (1:200 from Invitrogen, Burlington, ON, Canada) for $1 \mathrm{~h}$ at room temperature and then left to dry in the dark covered with antifade fluorescent mounting medium cover slips.

Double labeling. Human brain sections with subacute infarcts were treated with rabbit anti-XIAP antibody, incubated with goat anti-rabbit HRP and then XIAP staining was detected by DAB substrate kit for peroxidase as described above. Same sections were then treated with antibody against neurofilaments (anti-chicken NF-H; 1:500 from Chemicon, Temecula, CA) for $1 \mathrm{~h}$ at room

Table 1. Relevant clinical data of patients and controls included in the study

\begin{tabular}{|c|c|c|c|c|c|}
\hline Case & Sex/Age & Infarct territory & Cause of death & $\begin{array}{l}\text { Infarct } \\
\text { type }\end{array}$ & $\begin{array}{l}\text { Other diagnosis and/or } \\
\text { complications }\end{array}$ \\
\hline 1 & $\mathrm{~F} / 1.5 \mathrm{wks}$ & R Hippocampus & Perinatal asphyxia & Acute & IVH/refractory seizures \\
\hline 2 & $\mathrm{~F} / 1.5 \mathrm{mo}$ & Medulla & Sepsis & Acute & \\
\hline 3 & $\mathrm{~F} / 14 \mathrm{yrs}$ & L occipital cortex & Sepsis & Acute & Aplastic anemia/liver \& BMT \\
\hline 4 & $\mathrm{~F} / 1.5 \mathrm{mo}$ & $\mathrm{R}$ basal ganglia & $\begin{array}{l}\text { Diaphragmatic hernia/multiorgan } \\
\text { failure }\end{array}$ & Acute & Pulmonary hypertension/ ECMO \\
\hline 5 & $\mathrm{~F} / 15 \mathrm{yrs}$ & $\mathrm{R}$ frontal cortex & $\begin{array}{l}\text { Respiratory failure/multiorgan } \\
\text { injury }\end{array}$ & Acute & Aplastic anemia/BM T \\
\hline 6 & $\mathrm{M} / 1 \mathrm{yr}$ & Pons & Dilated cardiomyopathy & Subacute & \\
\hline 7 & $\mathrm{~F} / 3 \mathrm{yrs}$ & $\mathrm{L}$ thalamus & $\mathrm{CHD} /$ multiorgan failure & Subacute & $\begin{array}{l}\text { Shone's syndrome/prolonged } \\
\text { ECMO }\end{array}$ \\
\hline 8 & $\mathrm{M} / 1 \mathrm{wk}$ & L temporal cortex & $\mathrm{CHD}$ & Subacute & \\
\hline 9 & $\mathrm{~F} / 5.5 \mathrm{mo}$ & Medulla & $\begin{array}{l}\text { Cardiac arrest of unknown } \\
\text { etiology }\end{array}$ & Subacute & \\
\hline 10 & $\mathrm{~F} / 3$ wks & Pons & Neonatal meningitis & Subacute & \\
\hline 11 & $\mathrm{M} / 3 \mathrm{mo}$ & $\mathrm{L}$ thalamus & $\mathrm{CHD} /$ multiorgan failure & Subacute & Esophageal atresia/ECMO \\
\hline 12 & $\mathrm{~F} / 3 \mathrm{mo}$ & $\mathrm{R}$ thalamus & Necrotizing pneumonia & Subacute & DiGeorge syndrome/CHD/ECMO \\
\hline 13 & $\mathrm{M} / 4 \mathrm{mo}$ & $\mathrm{R}$ frontal cortex & $\begin{array}{l}\text { Necrotizing bronchiolitis/withdraw } \\
\text { care }\end{array}$ & Subacute & $\begin{array}{l}\text { Klebsiella sepsis/prolonged } \\
\text { ECMO }\end{array}$ \\
\hline 14 & $\mathrm{M} / 4 \mathrm{mo}$ & $\mathrm{R}$ basal ganglia & CHD & Subacute & $\begin{array}{l}\text { Multiorgan failure/prolonged } \\
\text { ECMO }\end{array}$ \\
\hline 15 & $\mathrm{M} / 6 \mathrm{mo}$ & L Calcarian cortex & Transposition of great vessels & Chronic & Multiorgan failure \\
\hline 16 & $\mathrm{M} / 11 \mathrm{yrs}$ & Midbrain & High cervical cord injury & Chronic & \\
\hline 17 & $\mathrm{~F} / 5 \mathrm{yrs}$ & R Frontal cortex & Autoimmune hemolytic anemia & Chronic & Severe bronchiectasis \\
\hline 18 & $\mathrm{~F} / 1 \mathrm{yr}$ & L Calcarian cortex & Down's Syndrome/CHD & Chronic & Pulmonary hemorrhage \\
\hline 19 & $\mathrm{~F} / 8 \mathrm{mo}$ & $\mathrm{R}$ basal ganglia & $\mathrm{CHD}$ & Chronic & $\begin{array}{l}\text { Chromosome } 22 \mathrm{q} \\
\text { deletion/ECMO }\end{array}$ \\
\hline Controls & & Normal brain sections & & & \\
\hline 1 & F/9 yrs & $\mathrm{R}$ frontal cortex/Midbrain & Anaplastic large cell lymphoma & & \\
\hline 2 & $\mathrm{M} / 2 \mathrm{mo}$ & $\mathrm{L}$ thalamus & Sudden death/RSV & & \\
\hline 3 & $\mathrm{~F} / 1 \mathrm{yr}$ & L Calcarian cortex & Asphyxia & & \\
\hline 4 & $\mathrm{~F} / 13 \mathrm{yrs}$ & $\mathrm{R}$ basal ganglia & Multiorgan failure post BMT & & \\
\hline 5 & $\mathrm{~F} / 3$ wks & Pons/L hippocampus & SUD & & \\
\hline
\end{tabular}

BMT indicates bone marrow transplant; CHD, congenital heart disease; ECMO, extracorporeal membrane oxygenation; IVH, intraventricular hemorrhage; L, left; R, right; SUD, sudden unexplained death. 


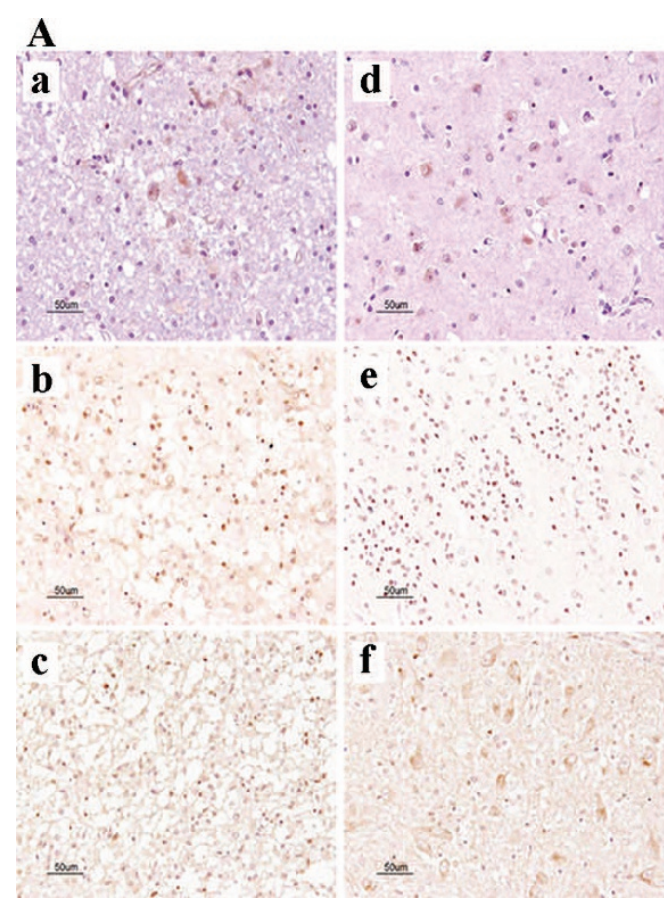

B

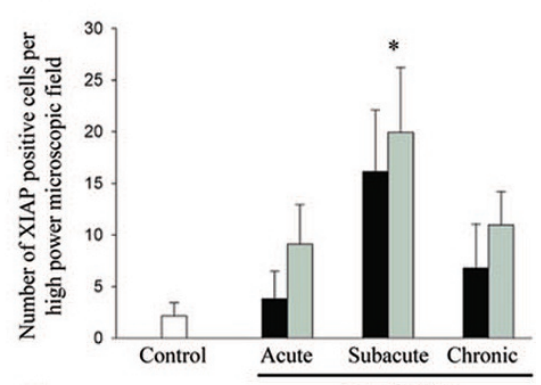

C Age of infarct

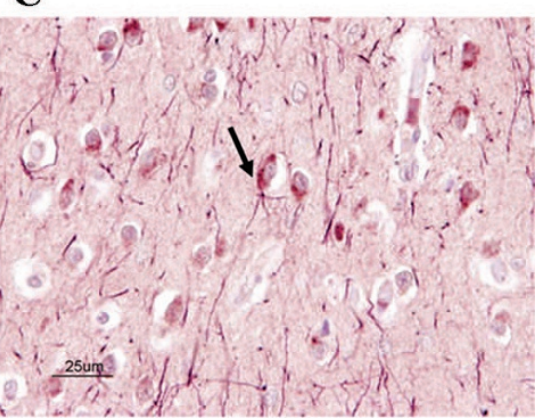

Figure 1. Neuronal XIAP expression increased in ischemic human developing brain. A, Immunohisotochemical staining of brain sections from children with acute (top row), subacute (middle row) or chronic infarct (bottom row) showed an increase in XIAP expression in the core $(a-c)$ and penumbra $(d-f)$ after ischemic injury. Brown color denotes XIAP positive cells. $B$, XIAP positive cells were counted in at least four high power microscopic fields $(40 \times)$ per core (black bars) and penumbra (gray bars) in each specimen using Image $\mathrm{J}$ computer software (National Institutes of Health, Bethesda, MD). XIAP expression (mean $\pm \mathrm{SE}$ ) increased in core and penumbra of acute, subacute and chronic infarcts. The most significant increase was in the penumbra of subacute infarcts compared with controls $* p<0.05$. $C$, Brain sections with subacute infarcts were treated with neurofilament (neuronal marker) and XIAP antibodies. XIAP and neurofilament staining were detected with $\mathrm{DAB}$ substrate kit for peroxidase (brown) and VIP substrate kit for peroxidase (purple) respectively. Colocalization of $\mathrm{XIAP}$ and neuronal marker staining was observed in injured neurons (arrow; 400×). temperature, washed and then treated with rabbit anti-chicken biotin (1:200) followed by avidin and biotinilated HRP complex (Vectorstain ABC kit from Vector Laboratories). Neurofilament staining was detected using VIP substrate kit for peroxidase (Vector Laboratories).

Statistical analysis. Experimental groups were compared using KruskalWallis analysis of variance on rank with post-hoc Dunn's method for pairwise comparison of subgroups since normality or equality of variance was not present. Normality was evaluated by the Kolmogorov-Smirnov test. Equality of variance was determined by the Levenne test. Results were considered to be statistically significant if $p<0.05$. All data were presented as mean \pm SE and statistical analysis was done using SigmaStat Software (v3.5, Dundas Software Ltd. and TE Subsystems Inc. Germany, 2006).

\section{RESULTS}

Patient population. A total of 19 patients (mean age, $33.5 \mathrm{~m}$ ) with a neuropathologic diagnosis of cerebral ischemic infarct met the inclusion criteria of our study. Of these 19 patients, 5 had acute infarcts, 9 had subacute infarcts, and 5 had chronic infarcts. The average time between death and autopsy was $15.6 \mathrm{~h}$ for acute infarcts (range, 2-29 h), $19 \mathrm{~h}$ (range, 7-37 h) for subacute infarcts, and $13.6 \mathrm{~h}$ (range, 7-19 h) for chronic infarcts. The clinical demographics on patients and controls $(n=5)$ are shown in Table 1 .

Increased XIAP expression in the human developing brain after ischemic injury. Slight elevation in XIAP expression was observed in the penumbra of acute infarcts. This elevation was more evident in core and penumbra of subacute infarcts compared with controls. In chronic infarcts, XIAP expression was reduced to levels similar to those seen in the acute infarcts (Fig. 1A). Elevated XIAP expression reached statistical significance in the penumbra of subacute infarcts compared with controls (Fig. 1B). There were no gender differences in XIAP expression in the core and penumbra of subacute infarcts (data not shown).

Double staining using XIAP and neurofilament (neuronal marker) antibodies showed cytosolic XIAP expression in neurons of developing human brain (Fig. 1C).
Prolonged increase in XIAP expression in the ischemic neonatal rat brain. Normal brain parenchyma shown by $\mathrm{H}$ and E staining directly adjacent to the ischemic "core" was defined as the peri-infarct or "penumbra" (Fig. 2A). XIAP expression reached a maximum at $48 \mathrm{~h}$ and then decreased with time in the core of the infarct (Fig. $2 B$ and $C$ ). The peri-infarct, on the other hand, showed a progressive increase in XIAP expression that continued for at least $1 \mathrm{wk}$ after the HI injury (Fig. 2B). The increase in XIAP expression was significantly higher by $24 \mathrm{~h}$ postischemic injury compared with controls and continued to increase in the peri-infarct but not the core $7 \mathrm{~d}$ postischemic injury (Fig. 2C). The number of XIAP positive cells was significantly higher in the peri-infarct compared with the core of the infarct by $7 \mathrm{~d}$ after hypoxicischemic injury (Fig. 2C). There was minimal expression of XIAP before $24 \mathrm{~h}$ postischemic injury (data not shown). XIAP was not expressed in any of the control animals or in the contralateral hemisphere.

Inverse pattern of caspase-3 expression compared with XIAP in the ischemic neonatal rat brain. Activated caspase-3 expression was maximal at $24 \mathrm{~h}$ and then decreased with time in the core and peri-infarct of ischemic neonatal rat brain (Fig. $3 A$ ). However, the number of caspase-3 positive cells was significantly higher in the core compared with both controls and to the peri-infarct at 24,48 and, $72 \mathrm{~h}$ postischemic injury (Fig. 3B).

\section{DISCUSSION}

In this study, we have shown that 1) neuronal XIAP expression is up-regulated in developing human and rat brain after ischemic injury; 2) the increase was delayed in both species by at least $24 \mathrm{~h}$ postischemic injury and sustained for up to $7 \mathrm{~d}$ in the rat pup; 3) XIAP expression was 


\section{A}

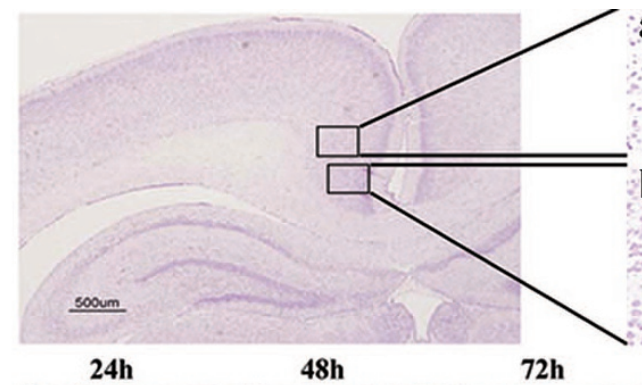

B

Core
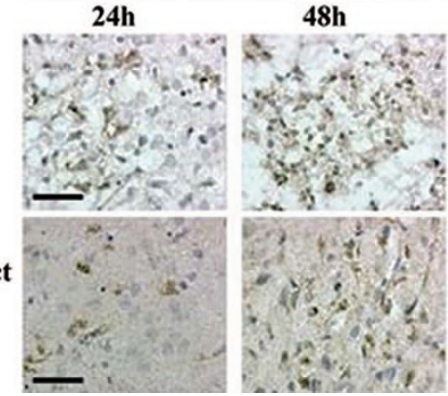

72h
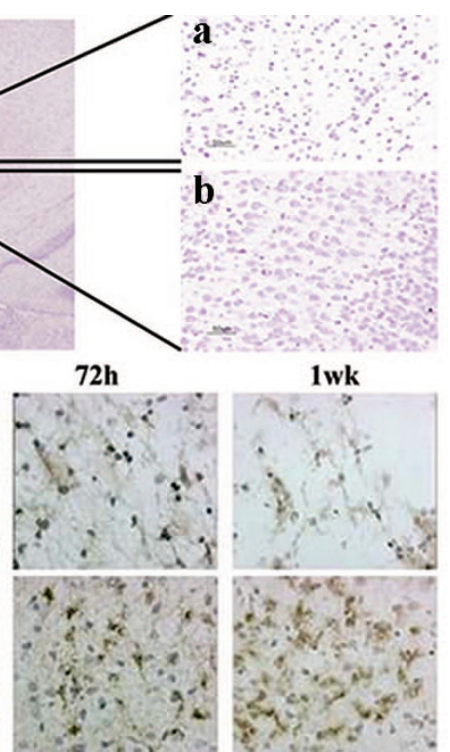

C

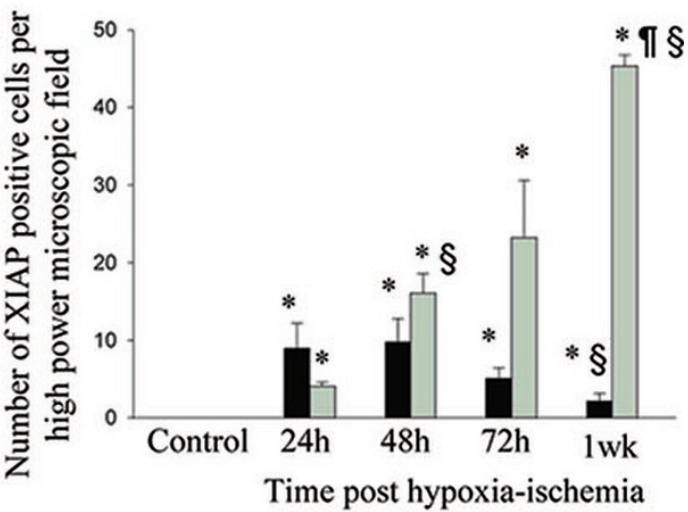

Figure 2. XIAP expression is increased in the peri-infarct area compared with the core of ischemic neonatal rat brain. $A$, Core of the infarct was defined by loss of normal hematoxylin and eosin staining pattern of brain parenchyma (inset $a$ ). Normal brain parenchyma directly adjacent to the ischemic core is the peri-infarct area (inset $b$ ). $B$, Immunhistochemical staining after hypoxic-ischemic injury showed an increase in XIAP expression in the peri-infarct area over time. Brown color denotes XIAP positive cells. Black bar indicates $50 \mu \mathrm{m}$. C, XIAP expression significantly decreased in the core (black bars) of the infarct by $7 \mathrm{~d}$ compared with 24, 48, and $72 \mathrm{~h}$ postischemic injury. The peri-infarct area (gray bars) showed a significant increase in XIAP expression reaching maximal observed expression at $1 \mathrm{wk}$ after hypoxic/ischemic insult. All data displayed as mean \pm SEM. $n=4$ for each time point. ${ }^{*} p<0.05$ when compared with controls; ${ }^{\circledR} p<0.05$ when compared with each previous time point within the same region; "I $p<0.05$ when core and peri-infarct are compared within the same time point.

\section{A}
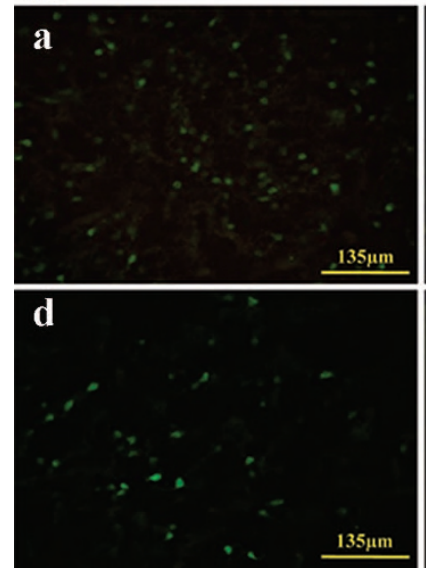
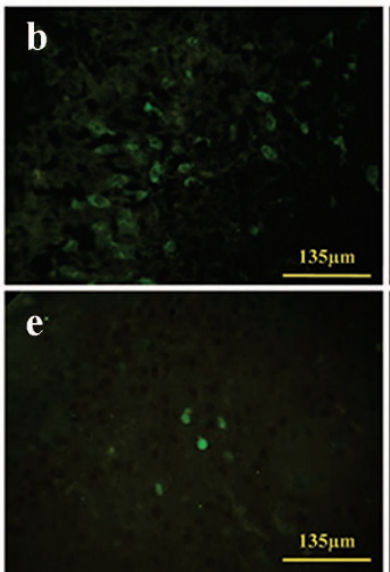
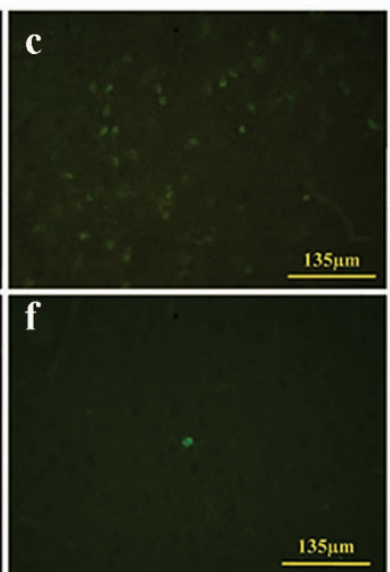

B

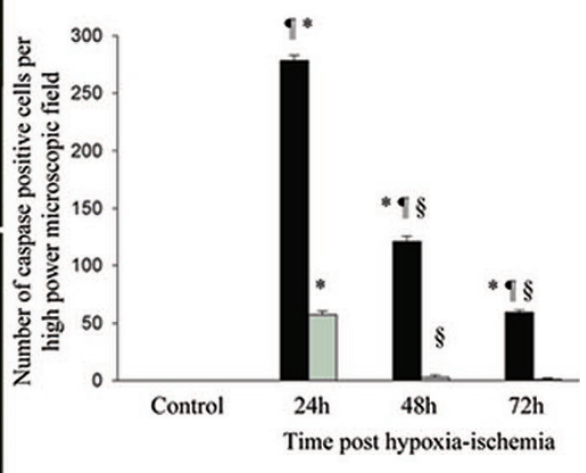

Figure 3. Caspase- 3 expression was significantly lower in the peri-infarct compared with the core of the infarct in neonatal rat brain. Immunofluorescent staining for activated caspase- 3 decreased with time in core $(a-c)$ and peri-infarct $(d-f)$ of ischemic neonatal rat brain at $24 \mathrm{~h}$ (top row), $48 \mathrm{~h}($ middle row), and $72 \mathrm{~h}$ (bottom row) (A). However, the number of caspase-3 positive cells remained significantly higher in the core (black bars) compared with the peri-infarct (gray bars) at all time points tested $(B) .{ }^{*} p<0.001$ when compared with controls; ${ }^{\circledR} p<0.001$ when compared with each previous compared with each previous time point within the same region; ${ }^{\text {Il }} p<0.001$ when core and peri-infarct are compared within the same time point.

significantly higher in the ischemic penumbra compared with the core of the infarct in both humans and rats and 4) The increase in XIAP expression was concurrent with a reduction in activate caspase- 3 in the peri-infarct area of neonatal rat brain.

To our knowledge, this is the first study to investigate the role of XIAP in the human developing brain and show a significant increase in neuronal XIAP expression in the penumbra of subacute ischemic infarcts. The neuronal expression of XIAP in human ischemic brain, we found, is in keeping with previous studies showing XIAP in cerebral neurons of neonatal mice (12), adult rat (17), and mice (18) brain after ischemic injury. We have previously shown that apoptotic cell death persists for several days in the ischemic human developing brain and that the number of caspase- 3 positive cells significantly decreased in the penumbra of subacute compared with acute infarcts (10). Increasing XIAP expression in the penumbra of subacute infarcts may play a role in inhibiting both caspase-dependent and -independent apoptosis in ischemic developing brain $(5-6,10)$.

Several investigators have studied apoptosis in autopsy brain tissue using morphologic criteria for apoptotic nuclei in addition to techniques such as DNA fragmentation labeling using TUNEL $(19,20,21)$ or staining methods for specific 
antibodies directed to caspase-3 (19,20-23) or apoptosisrelated proteins $(23,24)$. However, postmortem delay and tissue fixation techniques may affect apoptosis and apoptosisrelated protein detection methods $(21,25)$. In our study, the postmortem delay to autopsy was similar among the three groups of patients so the impact of such a delay should be the same for all specimens. Further, we were comparing specimens to themselves (core $v s$. penumbra) so the effects of postmortem delay for different regions in the same samples should be equivalent. Although it is conceivable that the amount of XIAP expression was underestimated in our autopsy specimens, it has been shown that the TUNEL detection method is reliable when tissue is fixed up to $48 \mathrm{~h}$ postmortem (21). Our longest postmortem delay to autopsy was $37 \mathrm{~h}$.

The characterization of XIAP temporal expression in ischemic human developing brain reported in this study is invaluable for any translational research investigating a therapeutic approach based on potentiation of antiapoptotic pathways. However, a potential weakness in this study is the wide age range of included patients. Ideally, patients would be divided into subgroups of neonates, early childhood, and late childhood to assess the difference in the response to ischemic injury as the brain matures. This proved to be very difficult due to the scarcity of human tissue. Nevertheless, we tried to address this issue by analyzing the data with and without including children older than $10 \mathrm{y}$ of age. The profile of XIAP expression in the acute, subacute, and old infarcts did not differ between the two data sets (data not shown). However, the impact of brain maturity on caspase-dependent and -independent apoptotic pathways should to be addressed in detail in future studies. Other limitations in using human tissue include the variability of brain regions affected by ischemia and the uncertainty in clinically determining the age of the infarct. We have previously shown that there was no significant difference in caspase-3 expression between infra- and supratentorial ischemic lesion in the human developing brain (10). All of the included patients were critically ill (Table 1) and heavily sedated. Thus, timing of neurologic deterioration due to cerebral infarct was difficult to determine clinically so we used the pathologic characteristics to determine the age of the infarcts. Because of all these limitations in using human tissue, we investigated the temporal and spatial expression of XIAP in a more controlled experimental paradigm using the RiceVannucci rat model of neonatal stroke. The brain maturity of a 7-d-old rat used in this model corresponds to a brain of human term infant (26).

There are conflicting data on XIAP expression after hypoxic-ischemic injury in rodent developing brain. Russell et al. (13) reported a reduction in XIAP expression in hypoxicischemic neonatal rat brain. Wang et al., (12) on the other hand, reported that XIAP expression peaked at $24 \mathrm{~h}$ and continued to be detected at $72 \mathrm{~h}$ posthypoxic-ischemic injury in neonatal wild-type mice. They also reported the presence of XIAP positive cells in the infarct margin but it was not clear whether the degree of XIAP expression in this area changed with time. Our study confirmed the up-regulation of XIAP expression in the ischemic developing rat brain and added a considerable depth of information on temporal and spatial expression of XIAP by providing quantitative data showing that XIAP expression continued to increase in the peri-infarct for several days (beyond $72 \mathrm{~h}$ ) after hypoxic-ischemic injury in neonatal rat brain. A prolonged increase in XIAP expression was not seen in the ischemic human developing brain. This discrepancy could be explained by the fact that the chronic infarcts included in the human study were older than $7 \mathrm{~d}$ which was the longest post-HI time point at which XIAP expression was assessed in the ischemic neonatal rat brain.

In adult rat brain, however, a nonsignificant increase in XIAP expression was detectable at $48 \mathrm{~h}$ in the core of the infarct after transient focal ischemia (27). The pattern of XIAP expression in the infarcted core of adult rat brain (27) was similar to neonatal rat brain as reported in our study where we noted an early transient increase followed by decline in XIAP expression. However, our study showed that unlike reports on adult rat brain, XIAP expression continued to increase in the peri-infarct area of neonatal rat brain. This increase was detected for more than $1 \mathrm{wk}$ after the hypoxic-ischemic insult whereas XIAP expression declined to the lowest level by $24 \mathrm{~h}$ postmiddle cerebral artery occlusion in the penumbra of adult rat brain (28). The explanation for these differences between adult and neonatal rat brain after ischemic injury is not clear yet. Apoptosis is a key mechanism in the ongoing modeling and remodeling that occur in the developing brain. Therefore, it is possible that increased levels of antiapoptotic proteins such as XIAP can only be detected in stress situations such as ischemia. This may be achieved by developmental variations in the expression of proteins regulating XIAP's activity such as second mitochondrial activator of caspase (Smac) (29), high-temperature requirement serine protease A2 (HtrA2) (30), and XIAP-associated factor 1 (XAF-1) (31). Further investigations of XIAP regulating proteins are warranted in the developing brain after ischemic injury.

The temporal and spatial expression profile of activated caspase-3 was the inverse of XIAP expression in the ischemic neonatal rat brain. Activated caspase-3 expression progressively decreased with time in the core and peri-infarct but remained significantly higher in the core compared with periinfarct at all time points. This reversed expression of caspase-3 compared with XAIP was also observed in the human developing brain where caspase-3 expression decreased (10) and XIAP increased in the penumbra of subacute infarcts. These results suggest that one of the potential mechanisms of XIAP-mediated neuroprotection is by inhibiting caspase-dependent apoptosis (5) in the ischemic developing brain. We have previously shown that caspase-3 was minimally expressed in the normal human developing brain (10). Here, XIAP was also minimally expressed in the control human specimens. Therefore, XIAP expression may be triggered by ischemia-induced apoptosis which may explain the low levels of XIAP in acute compared with subacute infarcts given that apoptosis is a delayed process in the ischemic developing brain (7-9). 
With the mounting evidence that apoptosis contributes to neuronal cell death after ischemic injury in developing brain $(7,10,11)$, physiologic and pharmacologic inhibitors of apoptosis are being actively investigated as potential therapeutic interventions. The potency of apoptotic suppression manifested by XIAP (32) makes it a natural candidate for therapeutic intervention in pathologic processes involving cellular apoptosis such as ischemic injury. Multiple studies in ischemic adult rat $(11,27,28)$ and mice (18) brain showed a neuroprotective effect of XIAP by inhibiting caspase activity. Over-expression of XIAP in neonatal mice brain decreased tissue loss by $40 \%$ (12). Transgenic expression of human FGF-1 in ischemic neonatal rat brain showed similar neuroprotective effects by inducing XIAP expression (13). Neuroprotection shown in these studies by XIAP was mediated by inhibiting caspase-dependent apoptosis. However, XIAP has also been shown to block caspase-independent cell death $(5,6)$. This may be an important pathway for cell death after ischemic injury in the human developing brain (10). Given the results of these studies taken together with our findings of delayed increase in XIAP expression after hypoxicischemic injury in the developing brain, we propose that potentiation of XIAP expression early (first $24 \mathrm{~h}$ ) after ischemic injury is a conceivable neuroprotective strategy for the developing brain.

Acknowledgments. We thank Hui Shi and Min Qiao for their excellent technical expertise.

\section{REFERENCES}

1. Birnbaum MJ, Clem RJ, Miller LK 1994 An apoptosis-inhibiting gene from a nuclear polyhedrosis virus encoding a polypeptide with Cys/His sequence motifs. J Virol 68:2521-2528

2. Crook NE, Clem RJ, Miller LK 1993 An apoptosis-inhibiting baculovirus gene with a zinc fingure-like motif. J Virol 67:2168-2174

3. Holcik M, Gibson H, Korneluk RG 2001 XIAP: apoptosis brake and promising therapeutic target. Apoptosis 6:253-261

4. Eckelman BP, Salvesen GS, Scott FL 2006 Human inhibitor of apoptosis proteins: why XIAP is the black sheep of the family. EMBO Rep 7:988-994

5. Silke J, Ekert PG, Day CL, Hawkins CJ, Baca M, Chew J, Pakusch M, Verhagen AM, Vaux DL 2001 Direct inhibition of caspase 3 is dispensable for the antiapoptotic activity of XIAP. EMBO J 20:3114-3123

6. Silke J, Hawkins CJ, Ekert PG, Chew J, Day CL, Pakusch M, Verhagen AM, Vaux DL 2002 The anti-apoptotic activity of XIAP is retained upon mutation of both the caspase 3- and caspase 9- interacting sites. J Cell Biol 157:115-124

7. Nakajima W, Ishida A, Lange MS, Gabrielson KL, Wilson MA, Martin LJ, Blue ME, Johnston MV 2000 Apoptosis has a prolonged role in the neurodegeneration after hypoxic ischemia in the newborn rat. J Neurosci 20:7994-8004

8. Zhu C, Wang X, Hagberg H, Blomgren K 2000 Correlation between caspase-3 activation and three different markers of DAN damage in neonatal cerebral hypoxiaischmia. J Neurochem 75:819-829

9. Pulera MR, Adams LM, Liu H, Santos DG, Nishimura RN, Yang F, Cole GM, Wasterlain CG 1998 Apoptosis in a neonatal rat model of cerebral hypoxia-ischemia. Stroke 29:2622-2630
10. Askalan R, deVeber G, Ho M, Jing M, Hawkins C 2006 Astrocytic-inducible nitric oxide synthase in the ischemic developing human brain. Pediatr Res 60:687-692

11. Xu D, Bureau Y, McIntyre DC, Nicholson DW, Liston P, Zhu Y, Fong WG, Crocker SJ, Korneluk RG, Robertson GS 1999 Attenuation of ischemia-induced cellular and behavioral deficits by X-chromosome-linked inhibitor of apoptosis protein overexpression in the rat hippocampus. J Neurosci 19:5026-5033

12. Wang X, Zhu C, Wang X, Hagberg H, Korhonen L, Sandberg M, Lindholm D, Blomgren K 2004 X-linked inhibitor of apoptosis (XIAP) protein protects against caspase activation and tissue loss after neonatal hypoxia-ischemia. Neurobiol Dis $16: 179-189$

13. Russell JC, Szuflita N, Khatri R, Laterra J, Hossain MA 2006 Transgenic expression of human FGF-1 protects against hypoxic-ischemic injury in perinatal brain by intervening at caspase-XIAP signaling cascades. Neurobiol Dis 22: $677-690$

14. Ellison D, Love S, Chimelli L, Harding BN, Lowe JS, Vinters HV 2003 Neuropathology; A Reference Text for CNS Pathology. Mosby, London, pp 199-201

15. Meng S, Qiao M, Lin L, Del Bigio MR, Tomanek B, Tuor U 2004 Correspondence of AQP4 expression and hypoxic-ischemic brain edema monitored by magnetic resonance imaging in the immature and juvenile rat. Eur J Neurosci 19:2261-2269

16. Meng S, Qiao M, Foniok T, Tuor U 2005 White matter damage precedes that in gray matter despite similar magnetic resonance imaging changes following cerebral hypoxia-ischemia in neonatal rats. Exp Brain Res 166:56-60

17. Korhonen L, Belluardo N, Lindholm D 2001 Regulation of X chromosome-linked inhibitor of apoptosis protein in kainic acid induced neuronal death in the rat hippocampus. Mol Cell Neurosci 17:364-372

18. Trapp T, Korhonen L, Besselmann M, Martinez R, Mercer EA, Lindholm D 2003 Transgenic mice overexpressing XIAP in neurons show better outcome after transient cerebral ischemia. Mol Cell Neurosci 23:302-313

19. Feigenbaum V, Gelot A, Casanova P, Daumas-Duport C, Aubourg P, Dubois-Dalcq M 2000 Apoptosis in the central nervous system of cerebral adrenoleukodystrophy patients. Neurobiol Dis 7:600-612

20. Mitsios N, Gafffney J, Krupinski J, Mathias R, Wang Q, Hayward S, Rubio F, Kumar P, Kumar S, Slevin M 2007 Expression of signaling molecule associated with apoptosis in human ischemic stroke tissue. Cell Biochem Biophys 47:73-86

21. Petito CK, Roberts B 1995 Effect of post-mortem interval on in-situ end-labeling of DNA oligonucleosomes. J Neuropathol Exp Neurol 54:761-765

22. Rossiter JP, Anderson LL, Yang F, Cole GM 2002 Caspase-3 activation and caspase-like proteolytic activity in human perinatal hypoxic-ischemic brain injury. Acta Neuropathol 103:66-73

23. Bernal F, Graus F, Pifarré A, Saiz A, Benyahia B, Ribalta T 2002 Immunohistochemical analysis of anti-Hu-associated paraneoplastic encephalomyelitis. Acta Neuropathol 103:509-515

24. Christie LA, Su JH, Tu CH, Dick MC, Zhou J, Cotman CW 2007 Differential regulation of inhibitors of apoptosis proteins in Alzheimer's disease brains. Neurobiol Dis 26:165-173

25. Anderson AJ, Su JH, Cotman CW 1996 DNA damage and apoptosis in Alzheimer's disease: colocalization with c-Jun immunoreactivity, relationship to brain area, and effect of postmortem delay. J Neurosci 16:1710-1719

26. Hagberg H, Bona E, Gilland E, Puka-Sundvall M 1997 Hypoxia-ischemia model in the 7-day-old rat: possibilities and shortcomings. Acta Paediatr Suppl 422:85-88

27. Althaus J, Siegelin MD, Dehghani F, Cilenti L, Zervos AS, Rami A 2007 The serine protease Omi/HtrA2 is involved in XIAP cleavage and in neuronal cell death following focal cerebral ischemia/reperfusion. Neurochem Int 50:172-180

28. Xu XH, Zhang SM, Yan WM, Li XR, Zhang HY, Zheng XX 2006 Development of cerebral infarction, apoptotic cell death and expression of X-chromosome-linked inhibitor of apoptosis protein following focal cerebral ischemia in rats. Life Sci 78:704-712

29. Wu G, Chai J, Suber TL, Wu JW, Du C, Wang X, Shi Y 2000 Structural basis of IAP recognition by Smac/DIABLO. Nature 408:1008-1012

30. Suzuki Y, Imai Y, Nakayama H, Takahashi K, Takio K, Takahashi R 2001 A serine protease, HtrA2, is released from the mitochondria and interacts with XIAP, inducing cell death. Mol Cell 8:613-621

31. Liston P, Fong WJ, Kelly NL, Toji S, Miyazaki T, Conte D, Tamai K, Craig CG, McBurney MW, Korneluk RG 2001 Identification of XAF1 as antagonist of XIAP anti-caspase activity. Nat Cell Biol 3:128-133

32. Holcik M, Korneluk RG 2001 XIAP, the guardian angel. Nat Rev Mov Cell Biol 2:550-556 